\title{
Entreatos: percursos e construções da psicologia na rede pública de ensino
}

\section{Interludes: psychology routes and constructions in the public teaching network}

\author{
Marisa Lopes da Rocha* \\ Professora do Departamento de Psicologia Social e Institucional e do Programa de \\ Pós-Graduação em Psicologia Social da Universidade do Estado do Rio de Janeiro - \\ UERJ, Rio de Janeiro, RJ, Brasil
}

\section{Kátia Faria de Aguiar**}

Professora do Departamento de Psicologia e Programa de Pós-Graduação em Psicologia da Universidade Federal Fluminense - UFF, Niterói, RJ, Brasil

\begin{abstract}
RESUMO
Neste artigo buscamos colocar em discussão a pesquisa-intervenção que vem se constituindo com a Rede de Proteção ao Educando no ensino público do Rio de Janeiro, abordando a formação dos trabalhadores sociais como um processo instigador de novos conceitos e práticas institucionais na perspectiva ético-estético-política. Para isso, damos visibilidade ao percurso que compõe o território escolar nas suas múltiplas forças, remetendo à reflexão sobre nossos atos, nossas implicações com as instituições em jogo e favorecendo escolhas sobre a melhor forma de trabalhar e viver. Concluímos, assumindo o desafio de (re)constituição de um campo de intervenção, problematizador e crítico, intensificador de encontros.

Palavras-chave: Formação do psicólogo, Psicologia e educação, Pesquisaintervenção, Micropolítica.
\end{abstract}

\begin{abstract}
In this paper we try to discuss an intervention-research that has been constituted in the Student Protection Network in Rio de Janeiro public teaching, approaching the formation of social workers as an instigating process of new institutional concepts and practices in the ethic-esthetic-political perspective. For this, we give visibility to the route that compounds the scholar territory in its multiple forces, remitting to the reflection about our acts, our implications with the institutions at stake and favoring the choices about the better ways of working and living. We conclude assuming the challenge of the (re)constitution of a problematizing and critical encounter intensifier intervention field.
\end{abstract}

Keywords: Psychologist formation, Psychology and education, Interventionresearch, Micro politics. 


\section{I ntrodução}

Gostaríamos de abrir a apresentação desse artigo, num esforço de delinear o campo de pesquisa e de intervenção no qual temos empreendido nosso trabalho com as instituições de formação. A aposta na pesquisa-intervenção, longe de se constituir em um abrigo da complexidade contemporânea, tem favorecido uma aventura por outras formas de pensar e fazer pesquisas, numa perspectiva éticoestético-política a que pretendemos dar corpo no curso desta escrita. Convém antecipar, no entanto, que tal perspectiva ganha consistência na micropolítica de produção de modos de subjetivação, um outro plano, dificilmente acessado nas políticas de saúde e assistência ou nas geradas por movimentos que vêm sendo denominados de críticos.

Diferentes caminhos poderiam nortear esse trabalho e não foi simples encontrar uma porta através da qual pudéssemos dar passagem a Félix Guattari e Gilles Deleuze para refletir sobre a subjetividade como produção. Como pensar a vida ou os nossos trabalhos em psicologia/educação pela micropolítica do cotidiano? Na perspectiva deleuziana, qualquer entrada é boa, desde que as saídas sejam múltiplas. Vamos arriscar um início através de alguns conceitos que possam se constituir em intercessores, ou seja, que possam interferir nesse processo a nosso favor, convidando-nos a caminhar por vias que, ao refletir sobre as práticas de formação no contexto da Educação, logrem um tríplice objetivo: (i) pensar a formação como criação de percursos em meio a múltiplas forças; (ii) remeter à reflexão sobre nossos atos, nossas implicações com as instituições em jogo, favorecendo escolhas sobre a melhor forma de viver; (iii) colocar o desafio de (re)constituição de um campo de intervenção, problematizador e crítico, intensificador de encontros. Eis o que se poderia denominar um paradigma ético-estético-político (GUATTARI, 1992).

Vale ainda evidenciar que esse artigo traz como referência as experiências do trabalho que vimos desenvolvendo com a Rede de Proteção ao Educando (RPE) ${ }^{1}$. Nesse encontro, psicólogos, assistentes sociais e educadores mergulham nas correntezas das tradições institucionais, nas políticas produtivistas, nos desejos por arejamento e, entreatos, interferem nas vidas que fazem diferença no cotidiano escolar, aceitando o desafio de construção de um outro lugar para os trabalhadores sociais, problematizando fazeres implicados com a produção social da existência. 


\section{Múltiplas forças que compõem os processos}

Desde que iniciamos nossas incursões no campo da educação, temos convivido com as constantes descontinuidades das políticas. A cada governo, novas medidas, novas chefias, novas urgências. As reiteradas mudanças ganharam, na comunidade escolar, a denominação de pacotes e, com ela, o sentido de que as determinações chegam sempre de cima, sem aviso prévio e sem direito à contestação. Os efeitos também já são velhos conhecidos e falam de desânimo, de falta de perspectiva, de insatisfações.

Nos últimos tempos, com o avanço das estratégias neoliberais, a produtividade e a aceleração têm dado o tom do desmapeamento gerador de perda de sentido dos processos, revelando que os descontinuísmos, para além de apresentar algumas inovações, parecem estar a serviço da manutenção e da reprodução dos hábitos instituídos. Se não são criados dispositivos para as parcerias, para abrir um tempo/espaço operador de processos de diferenciação, nos agarramos às estacas da estrutura, da velha organização que as políticas atuais dizem querer alterar. É voz corrente que muita coisa muda para nada mudar. Os resultados, o quantitativo, as estatísticas ganham o cotidiano da escola convocando a todos, de alguma forma, como partícipes nas montagens dos sempre novos mecanismos de monitoramento e de avaliação da produtividade. As resistências construídas entre as exigências do gerenciamento e as exigências colocadas pelo dia a dia de trabalho têm como desafio o enfrentamento da produção de urgências. A pergunta comum é "quem dá conta?"

A aceleração impressa nas ações urgentes, a solicitar respostas rápidas e imediatas, favorece a busca de recursos afetivos e cognitivos que habitam linhas duras de constituição do campo educativo. Frente à ameaça da não resolução de problemas ou do não cumprimento das tarefas solicitadas, o que aparece é a recorrência a padrões já conhecidos, quase automatizados, expressos em atitudes como: passar o problema adiante, encontrar culpados pelas ocorrências, ignorar ou rechaçar qualquer estímulo frente à impossibilidade de "dar conta de tudo"...

Tal como a paisagem vista de um trem em movimento, a cada aceleração, o que pode ser visto são borrões, flashes de cores, fragmentos de imagens e restos de objetos que incitam, de modo mais pregnante, reconhecimentos e, na sequência, o mal estar e a desistência de se ter qualquer acesso à paisagem. É que suspensa a potência de interferir, mesmo considerando sua variabilidade tática, as resistências acabam por ganhar formas que goram: investem reativamente na negação das forças de contenção ou radicalmente se dobram num movimento de ataque contra si mesmas. Acabam por reafirmar a inoperância de seus investimentos e, confirmando seu 
aparentemente sabido fracasso, no ápice de seu tensionamento, produzem adoecimentos.

Em tempos neoliberais, voltamos nossa atenção para as práticas de formação e, nos diálogos com a educação escolarizada, encontramos novas políticas para antigos problemas (inclusão, acessibilidade, infrequência, evasão, reprovação). Também encontramos outros personagens e discursos a imprimir modulações e intensidades em tensionamentos desde sempre pulsantes: conselho tutelar, teatro, grêmio, Estatuto da Criança e do Adolescente (ECA), drogas moderadoras, periculosidade, música, prevenção, segurança pública, jogos, risos, tráficos, especialistas... Entre eles, os especialistas na questão social - assistentes sociais e psicólogos.

Nesse momento da escrita nos damos conta de que essa poderia ser a introdução para diferentes experimentações que hoje temos em andamento. Essa primeira aproximação na constituição de um campo precisa ganhar outros contornos, é necessário trazer mais elementos, sinalizações, que avancem no traçado de um território e o acesso a alguns planos, favorecendo a abordagem de subjetivações e objetivações, como efeitos das práticas. Pensamos, então, na demanda a nós endereçada pela coordenação da RPE e escolhemos, ainda que sem tocar nos meandros de sua construção, trazer à cena alguns analisadores que, na abertura do campo de análise, apontam a criação de outros possíveis.

Vale lembrar que, pela porta da RPE, os psicólogos, há tempos personae non gratae nas escolas do município do Rio de Janeiro, voltam a ser convocados (re)acionando a velha aliança entre psicologia e educação.

Nossa entrada em cena no apoio ao processo de formação daqueles profissionais se dá a partir da solicitação por um "trabalho institucional" e traz outras linhas no contorno desse território. Dentre elas, a nossa inserção acadêmica, os vínculos anteriores com alguns ex-alunos participantes da rede e as referências sobre nossos trabalhos, por parte de vários psicólogos, têm funcionado favorecendo as condições de um processo de formação analíticoinstitucional. Além disso, na pactuação e análise permanentes dessas condições, temos sustentado os tensionamentos, alguns inelutáveis, que surgem no enfrentamento das problemáticas inerentes ao campo em questão. No processamento das análises importa destacar, por ora, a importância da construção de ferramentas que façam operar deslocamentos das queixas para a elaboração de demandas, como condição de emergência a funções de autonomia, tão caras à pesquisa-intervenção (AGUIAR; ROCHA, 2007; LOURAU, 1993).

No caminho da elaboração, explicitação e análise das demandas, a intensificação da produção de urgências aparece como um nó, ganhando centralidade nas problemáticas apresentadas pelos trabalhadores da educação, aqui incluídos psicólogos e assistentes 
sociais, permeando e contaminando os fazeres no 'chão da escola'. A lista de situações críticas e a multiplicação de afazeres é crescente e para ontem, impondo ligeireza e eficiência no cumprimento sob pena de desqualificação profissional. Nesse caminho, a escola não favorece histórias de vida em relação, mas a produção de casos, fraturando processos e fechando cada um em si mesmo.

A referência à falta de sentido da escola na atualidade aparece com insistência, ora como explicação para as dificuldades apresentadas pelas crianças, ora como justificativa do encadeamento de atos violentos que, diante da perplexidade de muitos, parecem consentidos e naturalizados. A demanda implícita, aqui, é por mais mecanismos de contenção e disciplinamento. Nos encontros de formação, escutamos sobre a falta de sentido da escola de hoje nas falas nostálgicas de uma escola do passado, nas falas de professores, nas reclamações dos pais, nas indisciplinas das crianças, nas análises de pesquisadores. Tais análises apontam as ambiguidades nas relações entre os alunos e a escola como assento para a ausência de referências que poderiam sustentar atribuições de novos sentidos para a escolarização. O desinvestimento e desaparelhamento da escola pública no contexto das políticas neoliberais (FRIGOTTO, 1995; GENTILI, 1995) e o esgotamento da escolarização como recurso na conquista da, ainda prometida e sempre adiada, mobilidade social aparecem como fortes argumentos para a falta de alternativas a serem atribuídas à importância da escola (SPOSITO, 1998).

Considerando a relevância dessas análises, queremos aqui dar ênfase àquelas da escuta atenta ao "jogo de fabricação" que se espreita no rebatimento das políticas no cotidiano das práticas (ALVES; GARCIA, 1999; SANTOS, 2006; VEIGA-NETO, 2005; MACHADO, 1994). Nesse caminho, encontramos que a abertura da escola para todos, realizada na ampliação e democratização do acesso, fez falar naquele espaço outras vozes, vozes dissonantes, vozes de qualquer um. E o que a partir daí parece se colocar como questão é a atualização, em atos, de um impasse inaugural do liberalismo, qual seja: o de ter que aliar a propalada igualdade cidadã e a diferença enquanto tensão imanente à presença do popular.

Frente a essa figuração que desafia os procedimentos pedagógicos, a linguagem e as estratégias de disciplinamento, o acolhimento de todos se fará numa busca constante de redução das tensões e das desestabilizações produzidas nos encontros. Na densificação da questão da diferença, o que ganha forma é "o diferente". Herdeira das injunções da modernidade, a escola atualiza a dicotomia homem $x$ mundo, professor que ensina $x$ aluno que aprende, professor $x$ especialista, saúde $\mathrm{x}$ loucura. Ela se apresenta habitada por um conjunto de pessoas, cada uma trazendo "em si" suas condições de existência e seus problemas. Os sujeitos são tomados isoladamente e a tentativa de compreendê-los gera classificações que fortalecem a 
lógica binária: a criança é lenta ou acelerada demais; é apática ou violenta; qual o diagnóstico?

Com o propósito de dar atenção a cada um, a tendência é a dos profissionais afirmarem o modelo que serve de crivo avaliativo do que se passa "nas pessoas", do que falta às pessoas frente ao padrão. Nos corpos isolados, o que pulsa e que poderia acessar a produção de sentido, tem sempre grandes chances de virar lamento e culpabilização. É para responder a esse campo problemático que o psicólogo, como especialista, é chamado: para afirmar a lógica das cenas, do que faz sentido, de quem faz sentido, atribuindo e/ou ratificando significado aos personagens.

\section{Reflexão sobre nossos atos, nossas implicações}

Entre nós, a história de constituição da psicologia como ciência e como profissão parece enfrentar desafios semelhantes àqueles colocados para a educação, quando confrontada com a denominada questão social. Como indica Ferreira Neto (2004), nos rastros dos eventos que marcaram a experiência política brasileira é que se observam, entre as décadas de 1980 e 1990, mudanças na formação e na atuação do psicólogo na direção das demandas das classes populares. Para esses profissionais vindos de cursos onde a hegemonia oscilava entre a psicologia experimental e a psicologia clínica (clássica/privada), o contato com as necessidades e as demandas populares nas instituições públicas, evidenciou a complexidade do campo e incitou outros fazeres. Podemos dizer que - que aparece como pregnante nas tendências das práticas é a consideração do contexto social da clientela, implicando a procura por novos referenciais teóricos.

$\mathrm{Na}$ psicologia como na educação o social, tornado indicador geográfico (favela) e econômico (pobre), desafia concepções e inspira a procura por outros instrumentos de trabalho. A consideração do contexto, embora importante, não foi e não é suficiente para desmontar as referências do modelo médico veiculado nas práticas psi (FERREIRA NETO, 2004). Os diagnósticos, as classificações nosológicas e as terapêuticas, no encontro com a escola, ganham e emprestam a ela o sentido de contenção e de controle.

Avançando no traçado de nosso campo, anotamos que talvez não seja por acaso que os psicólogos possam ser deslocados do campo de atuação clínica para o da educação, sem que isso, em princípio, formule questões no que tange aos referenciais de formação e trabalho.

Lidamos com escolas fragmentadas, sendo elas mesmas unidades isoladas na rede das demais instituições que intervêm na educação e com as quais a escola poderia fazer alianças (ROCHA; UZIEL, 2008). Tal segregação tira de foco as análises dos efeitos dos modos de funcionamento institucional e, neste sentido, deixa de pensar os 
sujeitos como efeitos da conjugação de diferentes práticas sociais políticas, econômicas, culturais, pedagógicas. Ou seja, como singularizações das intensidades que faz a vida das comunidades em que se constituem e dos dispositivos educacionais vigentes (ROCHA, 2002). Analisar as tradições, as práticas, os modelos, as mudanças legais, isso é coisa que fica para "os especialistas", "os pesquisadores", não são pensadas pelos que constroem o dia-a-dia da sala de aula.

De todo modo, o que hoje encontramos entre os profissionais é uma quase unanimidade no que se refere à mudança de atitude na atuação do psicólogo na escola. Críticos ao lugar que Ihes é atribuído de agentes de normalização, de controle e de silenciamento, interrogam sobre o que fazer. Diante dessa quase unanimidade, somos incitadas a vasculhar os processos, a investigar os detalhes: como se operacionaliza a postura crítica frente ao que se pede ao psicólogo na escola? O que seria efetivamente trair nosso encargo social?

Nas tentativas e disputas pelos caminhos de resolução desse estado de coisas, observamos hoje a (re)ativação de duas forças que, em diferentes tempos, aparecem ora mais, ora menos intensificadas e que instauram tensões no campo em questão.

Uma primeira força traz a velha aliança entre psicologia e cientificismo, observado em sua plenitude no saber médico. As marcas dessa aliança nos estudos da subjetividade, nas práticas psi e no cenário da educação já foram debatidas à exaustão em diversos trabalhos (MOYSÉS, 2001; ROCHA; AGUIAR, 1997; MACHADO; SOUZA, 1997). Tais análises falam de um caminho resolutivo para os impasses nos processos de formação que investem na busca de uma só linha de causalidade individualizante, no determinismo das condições. Esse caminho que opera assim o apagamento dos rastros da multiplicidade de linhas que desenham as condições de emergência de um problema. Nesse sentido, o encadeamento de interpretações leva necessariamente ao fechamento do campo de análise e a procedimentos que pretendem a restauração - de um indivíduo, de um grupo, de uma coletividade.

Uma segunda aliança que se estabeleceu fazendo frente àquela, foi o enlace entre psicologia e história. Essa linha de força convoca o determinismo das condições para com ele afirmar o necessário e incondicional posicionamento das ciências a serviço da emancipação dos setores oprimidos e excluídos da história. Para além das críticas à educação e ao desempenho da escola, apresentam-se inúmeras contribuições sobre a especificidade das linguagens, das etnias, dos gêneros, visando adequar métodos, materiais e processos à realidade das classes populares. Nessa aliança que reativa a memória das lutas sociais pela educação, as condições sócio-econômicas passam ao centro da cena e fazem das comunidades e da contextualização 
referências para o enfrentamento dos impasses. O imperativo da restituição de uma dívida histórica atravessa a formação dos trabalhadores sociais, politizando as práticas e afirmando caminhos para o reconhecimento "dos diferentes" (PATTO, 1993; BOCK, 2003). Nos encontros da psicologia com a educação, duas forças hegemônicas das nossas tradições parecem ganhar destaque no enfrentamento das desestabilizações e nas disputas pela produção de sentidos na escola, dualizando o campo de luta: os procedimentos e terapêuticas de medicalização e a consciência e tomada de posição política.

Importa ressaltar que essas alianças co-existem, se atualizam e desenham novas e até mesmo inusitadas figurações no âmbito das forças em luta, no presente. Observamos, por exemplo, que a depender da composição que se estabeleça entre as forças em tensão, podemos encontrar desvios nos efeitos esperados dessas alianças. Assim, nem sempre acolher a demanda de acompanhamento de uma criança é equivalente à privatização das questões geradas no sócius. Do mesmo modo, a consideração do contexto ou o trabalho com grupo, não garantem a abertura à diferença, podendo estar a serviço do apaziguamento de inquietações ou até mesmo de justificativa para procedimentos medicalizantes.

Entre o ato médico e o ato político o que não se altera é a concepção de política, de subjetividade e o modo de abordar suas intrincadas relações.

Guattari e Rolnik (1986), através das análises micropolíticas, pretendem escapar ao binarismo (re)produzido a partir de sucessivas individualizações, de totalizações fragmentadoras pressupostas no 'em si', buscando os rastros dos movimentos, numa rede rizomática?. No entre-pessoas, pessoas e coisas, existe tensão produtiva (de intensidade variada) que nos leva a pensar, a agir, que nos potencializa ou despotencializa. Cada um de nós é resultante de um processo de vida e é como cada um que habitamos o campo do visível, da representação, das constâncias.

Queremos evidenciar que o plano do invisível, do que ainda não foi pensado, não é menos real. $\mathrm{O}$ acesso às micropolíticas implica numa mudança de foco: a de colocar uma lupa nas intensidades que se produzem entre as pessoas, nas formações do desejo. Naffah Neto nos ajuda a compreender que a noção de desejo passa de produto de acontecimentos passados ao registro de produção eminentemente social, desejo que se constrói nos encontros. O desejo tem um aspecto revolucionário, não remete a objetos; é potência, é intensificação de campos de forças, "[...] pulsação imanente ao campo social nos movimentos de produção do real" (NAFFAH NETO, 1985, p. 25). 
O desejo permeia o campo social tanto em práticas imediatas, quanto em projetos muito ambiciosos. Por não querer me atrapalhar com definições complicadas, eu proporia denominar desejo a todas as formas de vontade de viver, de vontade de criar, de vontade de amar, de vontade de inventar uma outra sociedade, outra percepção do mundo, outros sistemas de valores [...]. O desejo é sempre o modo de produção de algo, o desejo é sempre o modo de construção de algo. (GUATTARI; ROLNIK, 1986, p. 215-216)

O que afeta as pessoas, implicando-as com o exercício da problematização, com a produção de outros sentidos de vida e de ação?

As relações ganham aqui o sentido de abordar a vida pelo meio, como máxima metódica. A escola é vista, então, como uma rede de intensidades de implicação coletiva que pode investir tanto na rotina, principalmente pelo lamento, assim como pode agenciar formas de resistência, de luta, construindo outros modos de vida institucional (SAIDÓN, 2002). Nesse sentido, a escola deixa de ser um conjunto de casos-problemas (abordagem que fala em natureza das pessoas) para constituir-se em um campo de forças socialmente produzido, manifestando-se de diferentes formas e podendo ser abordado pela análise coletiva dos hábitos, das naturalizações das cenas e dos procedimentos, da organização centralizada e vertical do sistema de ensino.

Afirmamos assim uma outra entrada no campo que busca marcar uma diferença daquela que tradicionalmente encontramos na psicologia referida à intersubjetividade, às inter-relações de indivíduos, de grupos, ou mesmo destes com a sociedade. Marcar essa diferença, mais que interpelar as dicotomias, é estar em meio às forças que as engendram, que configuram indivíduos, grupos e sociedade, como extremidades, nos encontros.

Como operar tal deslocamento? É com esse desafio que vamos continuar nosso traçado.

\section{O desafio de ( re)constituição de um campo de intervenção}

O processo de formação ao qual recorremos para agenciar as discussões aqui propostas tem exigido a composição de um outro campo de análise, com a proliferação de diálogos entre diferentes elaborações acerca da subjetividade, da história, da filosofia, da sociologia, da educação. Uma composição tecida de forma minuciosa e delicada a cada encontro, que implica revisitar referências construídas nos diferentes processos de formação dos integrantes do coletivo-RPE. Plano no qual podemos acessar forças que atuam no constrangimento das práticas, instruindo regulações e ratificando encargos, e tensionar outras que investem no desvio, no escape. Nesse exercício se fez necessária a constituição de um campo de 
intervenção, em permanente recriação, que é permeado por fluxos, materiais e imateriais (SANTOS, 1997a), advindos das escolas e atualizados nos encontros - e, por outros, próprios da singularização da experiência, no entre-nós.

Para tanto, o convite que fazemos é o de uma aproximação e atenção apurada ao cotidiano do trabalho, escutando suas reverberações. Como já discutimos em outro momento (ROCHA; AGUIAR, 2003) e em consonância com outros autores (HELLER, 1970, DE CERTEAU 1994, LEFEBVRE,1991, PENIN 1995, KOWARICK, 2000), podemos dizer que duas lógicas se enredam no cotidiano.

Uma primeira lógica é aquela que traz a equivalência entre 0 cotidiano e o vivido, traduz-se na rotina que faz a repetição de nossas vidas. Entendida como uma totalidade fechada, a cotidianidade é um sistema previsível, estável; num tempo linear, o futuro, contido no presente, é determinado pelo passado. O que aparece como pregnante são as constâncias e, com elas, a tendência à unidade imediata entre ação e pensamento, gerando o automatismo das atividades em que o útil ganha estatuto de verdade. Uma tendência econômica funcional a um sistema social dado que perpetua tradições, favorecendo estereotipias e preconceitos (PATTO, 1993).

Uma outra lógica do enredamento, que força a complexificação do cotidiano, se produz pela ruptura da rotina, por acontecimentos portadores de imprevisibilidade. A surpresa desconcertando nossas expectativas e nos obrigando a pensar, a inventar. A aceitação e o acolhimento da desestabilização pode favorecer o encontro com a alteridade, do outro-em-nós, como um estranho que nos inquieta e ao qual vamos tentar dar um significado (ROLNIK, 1995).

Aqui, o cotidiano contempla, ao mesmo tempo, constâncias e mutações, constituindo-se por/nas práticas atravessadas pelos valores, pelos princípios, pelas formas de ser/fazer/pensar possíveis em uma época da sociedade. O que evidencia que, para além de atualizações do paradigma cientificista hegemônico, vivemos experiências e agenciamos modos singulares de produzir ações, conceitos, formas de educar, práticas sociais...

O que importa é reafirmar que o cotidiano como paradoxo se constitui em uma idéia-chave em nossos percursos (AGUIAR; ROCHA, 2008).

A depender dos agenciamentos que se efetuam nos processos, 0 cotidiano pode ganhar densidade pela experiência que provoca o pensamento, nos fazendo criar o tempo produtor de novos conceitos, de outras práticas, de uma certa singularidade - cada um de nós é um modo único de expressar a multiplicidade que compõe o campo de forças que denominamos de social. "O múltiplo é não só o que tem muitas partes, mas o que é dobrado de muitas maneiras", afirma Deleuze (1991, p.14).

Mas o que encontramos, e que tem retornado com insistência, é a figura produzida na tradição filosófica ocidental, fruto da 
supervalorização do sujeito do racionalismo cartesiano, a que chamamos indivíduo. Nela, a subjetividade se apresenta ao mesmo tempo como universal (natureza humana) e interiorizada (particularidade $x$ totalidade). $O$ indivíduo nos remete às idéias de indiviso, essência e se ancora em dicotomias: subjetividade e objetividade, homem e meio, social e psiquismo.

No encadeamento dessas imagens, premido pelas urgências, pelos problemas e pelos casos que lhe são encaminhados, o psicólogo fecha seu foco na mediação de relações: entre professores, destes com o trabalho e com a comunidade, entre a família e a escola, etc. Poderíamos dizer, neste caso, que o psicólogo faz sua entrada, no campo, pelo plano das formas e que, fixando sua atenção nas extremidades das relações (por exemplo: professor $x$ aluno), favorece o aprisionamento das análises nos corpos, expandindo a privatização dos conflitos e a contração do espaço público. Um outro fator que também não contribui para a coletivização das práticas está no entendimento de que é no consenso (conformidade, concordância, unanimidade) que se dá o avanço do entendimento e dos desdobramentos das ações, sendo seu contrário, a discórdia, dissolução, decomposição. É importante perceber que quando reduzimos as margens dos embates da vida às relações de consenso e seu contrário, o que escapa é o dissenso (dissidência), condição de polêmica e de singularização de experiências.

Queremos dar relevo às relações de convivência enquanto desafio de criação de sempre novas normas, negociações que avançam e retrocedem no cotidiano como paradoxo: plano das forças em tensão que se compõe no entre-nós e plano das formas nos acordos possíveis a cada vez, expresso por nossas proposições. Esse é o caminho que fortalece a publicização das idéias e a dimensão de público como experimentação, plano do em comum. E, diverso do que tradicionalmente se possa pensar, tal plano é muito concreto, a abstração habita o todos, quem são todos? É em aliança com Pelbart (2008) que trazemos nosso entendimento para a existência do plano das afecções, do em comum

Ou seja, é a potência de vida da multidão, no seu misto de inteligência coletiva, de afetação recíproca, de produção de laço, de capacidade de invenção de novos desejos e novas crenças, de novas associações e novas formas de cooperação, como diz Maurizio Lazzarato na esteira de Tarde, que é cada vez mais a fonte primordial de riqueza do próprio capitalismo. Por isso mesmo este comum é o visado pelas capturas e seqüestros capitalísticos, mas é esse comum igualmente que os extrapola, fugindo-lhe por todos os lados e todos os poros. Sendo assim, seríamos tentados a redefinir - comum a partir desse contexto preciso. Parafraseando Paolo Virno, seria o caso de postular o comum mais como premissa do que como promessa, mais como um reservatório 
compartilhado, feito de multiplicidade e singularidade, do que como uma unidade atual compartida, mais como uma virtualidade já real do que como uma unidade ideal perdida ou futura. (PELBART, 2008, p.4)

A entrada micropolítica, apostando na abertura dos processos à dimensão inventiva, vai exigir das práticas a desconstrução da noção de indivíduo, em atos. E será entreatos, na abordagem da subjetividade como produção que se buscará iluminar a complexidade, as misturas, as tensões dos paradoxos, do que conjuga uma(s) coisa(s) e outra(s), de forma singular. Aqui a existência é ênfase no entrecruzamento de diversos vetores de subjetivação, e isso, segundo Guattari e Rolnik (1986), diz respeito menos à identidade, à ordem circunscrita das formas fixas e estáveis, e mais à singularidade, às modulações nos modos de ser/viver.

$\mathrm{Na}$ abertura ao plano das afecções, o fazer do psicólogo como analítica das formações do desejo desafia o pensamento em sua provisoriedade, e ganha potência pelas maneiras de agir nas situações diversas, pela variação de formas assumidas em diferentes circunstâncias. Nesse sentido, das indagações por identidades fixas, como cartões de acesso a qualquer lugar, passamos a construções de modos de subjetivação nas práticas entre nossos parceiros na conquista de outros possíveis na formação. Isso significa que experiência implica duração do tempo - duração em nós, intensificando o presente pela afecção (DELEUZE, 1966). Logo, o tempo não passa de forma linear e esperada na ordem passado, presente, futuro, como repetição, mas é também inventivo, intensivo, pois faz misturas e opera mudanças. Kastrup (1999) afirma que a experiência circunscreve as variações que foram sendo tecidas no curso do trabalho cotidiano para dar conta das atividades. As atividades subjetivam, são formas de fazer e de ser ao mesmo tempo, e isto está implicado com as artes do fazer de qualquer um, inclusive do psicólogo.

Dos problemas e das trocas de experiências, passamos às experimentações, ao exercício permanente de interceder a favor da instauração de um campo problemático, no qual o que interessa é explorar a qualidade dos caminhos, alguns dos quais, levam à constituição de novos problemas.

Nessa perspectiva, na escola estaria em discussão os usos dos corpos, do tempo, do espaço, os novos dispositivos de controle. Por exemplo, poderíamos colocar em análise as 'crianças hiperativas' que não correspondem às nossas expectativas de comportamento e de aprendizagem e que angustiam professores, pais e psicólogos. A essas crianças são endereçados procedimentos de encaminhamento a atendimentos (dentro das escolas) e de medicalização (em diversos equipamentos de saúde) como caminhos de resolução, a promover o 
foco da atenção necessária aos processos de escolarização (MONTEIRO, 2006). Os medicamentos que operam o controle redutor do campo de atenção das crianças, utilizados como solução ao que escapa do planejado, também funciona como obliterando o campo de análise dos profissionais, dos estudantes e das famílias.

A hiperatividade das práticas sociais, cada vez mais aceleradas para atingir os escores de produtividade, o bombardeio de informações e de atividades na vida das crianças e jovens, dentro e fora da escola, são dimensões de análise e de intervenção que vêm escapando da(s) ritalina(s) ao gosto dos laboratórios que prestam 'bons serviços'.

$\mathrm{Na}$ escola, poderíamos apontar para um devir professor-pesquisador, cuja gestão da atividade educacional é um movimento inventivo nos diferentes processos e aprendizagens em curso no ambiente escolar. Não se trata de abrir mão de uma formação consistente; trata-se de um outro sentido de consistência, não referido à acumulação de informações, mas ao manejo de dispositivos que sustentem um campo de indagação. Este devir mestre-aprendiz aponta um outro lugar para o professor, no qual autonomia é um exercício diário éticoestético e político na prática profissional.

Isso não significa que não existam cronificações institucionalizadas em meio às forças hegemônicas de uma época, de uma sociedade. Somos também personagens: "o psicótico", "o hiperativo", "o bom professor", "a mulher", "a mulher casada", uma infinidade de os, as, de artigos definidores dos sucessivos cortes já feitos em nossa cultura, em nossa sociedade, mas somos também forças em tensão (MACHADO, 1994). Mais ou menos em tensão, dependendo da situação e do quanto ela coloca em xeque a resistência de nossas carapaças, de nossas armaduras, fazendo, como diz Rolnik (1995) o corpo vibrar. "Louco ou são?" - perguntaríamos, recorrendo, aqui, a um binarismo frequente nas práticas psis. A resposta depende das situações e das questões que compõem nossas experiências a cada momento, aproximando-nos mais ou menos da loucura ou da sanidade. "Louco ou são?". Bem, diríamos "os dois", louco e são: existência que se faz entre as extremidades.

Chamamos mais uma vez Guattari e Rolnik (1986) em uma fala que expressa de forma interessante a questão de como ir além dos dualismos, particularmente entre sujeito e sociedade:

Quando vivemos nossa própria existência, nós a vivemos com as palavras de uma língua que pertence a cem milhões de pessoas; nós a vivemos com um sistema de trocas econômicas que pertence a todo um campo social; nós a vivemos com representações de modos de produção totalmente serializados. No entanto, nós vamos viver e morrer numa relação totalmente singular com esse cruzamento. O que é verdadeiro para qualquer processo de criação é verdadeiro para a vida. Um músico ou pintor está 
mergulhado em tudo o que foi a história da pintura, em tudo o que a pintura é em torno dele e, no entanto, ele a retoma de um modo singular. Isso é uma coisa. Outra é a maneira como essa existência, esse processo criativo será depois identificado em coordenadas sócio-históricas [...]. O que interessa à subjetividade capitalística, não é o processo de singularização, mas justamente esse resultado do processo, resultado de sua circunscrição a modos de identificação dessa subjetividade dominante. (GUATTARI; ROLNIK ,1986, p.69)

Se anteriormente evocamos a imagem de um trem em movimento para acessar alguns efeitos de uma temporalidade em crescente aceleração, para concluir queremos trazer a imagem do andarilho a cruzar paisagens e, com elas, compondo territórios (SANTOS, 1997b). Dando passagem aqui às instruções de um pajé, pensamos o andarilho num deslocamento bem localizado: entre o cerrado e a floresta tropical. Ali, nos diz o profeta-feiticeiro, encontramos um limite que, a um olhar apressado, pode nos levar de um território a outro apenas confirmando um visível contraste. No entanto, adverte o pajé, essa passagem, longe de ser apenas uma linha de fronteira, se faz também como um campo híbrido, de densidades variadas, onde se espreitam zonas sensíveis à construção de outros sentidos que não se ancoram nas extremidades, em nenhuma daquelas paisagens. O acesso a essa variabilidade das vidas que ali se tecem, e que inclui a nós mesmos, exige que habitemos essa zona por mais tempo ou, melhor seria, num outro tempo - o tempo da intensidade. É habitando esse tempo, na escuta atenta e paciente do silêncio, que nos chegarão outras imagens, outros sons, outros mundos, como criação de possíveis.

\section{Referências Bibliográficas}

AGUIAR, K.; ROCHA, M.L. Micropolítica e o exercício da pesquisaintervenção: referenciais e dispositivos em análise. Psicologia Ciência e Profissão, Brasília, n. 4, ano 27, p. 648-663, 2007.

A inclusão do conflito como estratégia de intervenção na escola. In: BOGAMINO, I. S.; TONDIN,C. F.; BRUXEL,K. (Orgs.). As práticas da psicologia social $\operatorname{com}(0)$ movimentos de resistência e criação. Porto Alegre: Abrapso Sul, 2008, p.35-45.

ALVES, N.; GARCIA, R.L. Atravessando fronteiras e descobrindo (mais uma vez) a complexidade do mundo In:

escola. Rio de Janeiro: DP\&A, 1999, p. 81-110.

O sentido da

BOCK A. M. B. (Org.). Psicologia e o compromisso social. São Paulo: Cortez, 2003.

DE CERTEAU, M. A invenção do cotidiano. 5.ed. Petrópolis: Vozes, 1994. 
DELEUZE, G. Le bergsonisme. Paris: PUF, 1966.

A dobra. Leibniz e o barroco. Campinas: Papirus, 1991.

FE RREIRA NETO, J.L. A formação do psicólogo - clínica, social e mercado. São Paulo: Escuta, 2004.

FRIGOTTO, G. Os delírios da razão. Crise do capital e metamorfose conceitual no campo educacional. In: GENTILI, P. (Org.). Pedagogia da exclusão e crítica ao neoliberalismo em educação. Petrópolis: Vozes, 1995, p.77-108.

GENTILI, P. Adeus à escola pública. A desordem neoliberal, a violência do mercado e o destino da educação das maiorias. In: - Pedagogia da exclusão: crítica ao neoliberalismo em educação.Petrópolis: Vozes, 1995, p. 228-252.

GUATTARI, F.; ROLNIK, S. Micropolítica. Cartografias do desejo. Petrópolis: Vozes, 1986.

GUATTARI, F. Caosmose. Um novo paradigma estético. São Paulo: 34, 1992.

HELLER, A. O cotidiano e a história. São Paulo: Paz e Terra, 1970. KASTRUP, V. A invenção de si e do mundo. Campinas: Papirus, 1999.

KOWARICK, L. Escritos urbanos. São Paulo: 34, 2000.

LEFEBVRE, H. A vida cotidiana no mundo moderno. São Paulo: Ática, 1991.

LOURAU, R. Análise institucional e práticas de pesquisa. Rio de Janeiro: EdUERJ, 1993.

MACHADO, A. M. Crianças de classe especial. Efeitos do encontro da saúde com a educação. São Paulo: Casa do Psicólogo, 1994.

MACHADO, A. M.; SOUZA, M.P.R. (Orgs.). Psicologia escolar: em busca de novos rumos. São Paulo: Casa do Psicólogo, 1997.

MONTEIRO, H. R. A medicalização da vida escolar. 2006. $114 \mathrm{f}$. Dissertação (Mestrado em Educação) - Faculdade de Educação, Universidade Federal do Estado do Rio de Janeiro, UNIRIO, Rio de Janeiro.

MOYSÉS, M. A. A. A institucionalização invisível: crianças que não aprendem na escola. São Paulo: Editora Mercado das Letras, 2001.

NAFFAH NETO, A. O inconsciente. um estudo crítico. São Paulo: Ática, 1985.

PATTO, M.H.S. A produção do fracasso escolar. São Paulo: Queiroz, 1993.

PELBART, P. P. Elementos para uma cartografia da grupalidade. In: SAADI, F; GARCIA, S. (Orgs.). Próximo ato: Questões da Teatralidade Contemporânea. São Paulo: I taú Cultural, 2008, p. 33-37.

PENIN, S. Cotidiano e escola. A obra em construção. São Paulo: Cortez, 1995. 
ROCHA, M. L. Contexto do adolescente. In : CONTINI, M. L. et al (Orgs.). Adolescência \& Psicologia. Concepções, práticas e reflexões críticas. Brasília: CFP, 2002, p. 25-32.

ROCHA, M. L.; AGUIAR, K. Práticas universitárias e a formação sóciopolítica. Anuário do Laboratório de Subjetividade e Política. v. 3/4, Niterói, p. 97-112, 1997.

ROCHA, M. L,; AGUIAR, K. Pesquisa-intervenção e a produção de novas análises. Psicologia Ciência e Profissão, Brasília, n. 4, ano 23, p.64-73, 2003.

ROCHA, M. L.; UZIEL, A. P. Pesquisa-intervenção e novas análises no encontro da psicologia com as instituições de formação In: CASTRO, L R.; BESSET, V. L. (Orgs.). Pesquisa-intervenção na infância e juventude. Rio de J aneiro: NAU Editora/FAPERJ, 2008, p.532-556.

ROLNIK, S. À sombra da cidadania: alteridade, homem da ética e reinvenção da democracia. In: MAGALHÃES, C. R. (Org.). Na sombra da cidade. São Paulo: Escuta, 1995, p. 143-170.

SAIDON, O. Clínica y sociedad. Esquizoanálisis. Buenos Aires/México: Grupo Editorial Lumen, 2002.

SANTOS, M. Metamorfoses do espaço habitado. 5.ed. São Paulo: Hucitec, 1997a.

A natureza do espaço. 2.ed. São Paulo: Hucitec, 1997b.

SĀNTOS, N. I. S. Escola Pública e Comunidade: Relações em D'obras. Vivência, Natal, v. 31, p. 62-77, 2006.

SPOSITO, M. P. A instituição escolar e a violência. Cadernos de Pesquisa da Fundação Carlos Chagas, São Paulo, v. 104, p.58-75, 1998.

VEIGA-NETO, A. Quando a inclusão pode ser uma forma de exclusão. In: MACHADO, A. D. et al (Orgs.). Educação Inclusiva. Direitos Humanos na Escola. São Paulo: Casa do Psicólogo, 2005, p. 55-70. WOLF, V. Entre os atos. São Paulo: Novo Século Editora, 2008.

\section{Endereço para correspondência}

Marisa Lopes da Rocha

UERJ, Rua São Francisco Xavier, 524, Instituto de Psicologia, 10 andar, Maracanã, CEP 20550-013, Rio de J aneiro - RJ, Brasil

Endereço eletrônico: marisalrocha@uol.com.br

Kátia Faria de Aguiar

UFF, Departamento de Psicologia, Campus do Gragoatá, Bloco O, São Domingos, CEP 24220-008, Niterói - RJ, Brasil

Endereço eletrônico: katiafaguiar@uol.com.br

Recebido em: 10/08/2009

Aceito para publicação em: 23/09/2009

Acompanhamento do processo editorial: Deise Mancebo e Roberta Carvalho Romagnoli 


\section{Notas}

* Pesquisadora CNPq, Doutora em Psicologia Clínica pela PUC/SP

** Doutora em Psicologia Social pela PUC/SP

${ }^{1} \mathrm{O}$ primeiro contato com a Rede de Proteção ao Educando (RPE), um Projeto macro funcional entre as Secretarias Municipais de Educação (SME) e Assistência Social (SMAS), composto por psicólogos e assistentes sociais, aconteceu no final de 2007, quando as coordenadoras responsáveis pelas ações da psicologia trouxeram a solicitação de apoio no sentido da construção de uma abordagem institucional para o trabalho do psicólogo. Ao longo de 2007, muitas tentativas de desenvolvimento de práticas integradas com os profissionais da assistência e com os educadores não se efetivaram, pois, segundo a coordenação, a formação de grande parte do grupo de psis, concursados para a clínica assistencial dos serviços de saúde municipais e os encaminhamentos/tratamentos cobrados pelas direções das escolas, nas tradições das expectativas do trabalho do psicólogo, dificultavam o avanço no sentido da viabilização de uma proposta interdisciplinar. Os 57 psicólogos que originalmente constituíram a equipe, embora concursados para atuar na Secretaria Municipal de Saúde (SMS), foram nomeados e lotados na SME para desenvolver e implementar a RPE. Num primeiro momento, esses profissionais foram lotados nos Centros de Referência em Assistência Social (CRAS) e Pólos de Atendimento Extraescolar (PAEE), sendo mais tarde vinculados diretamente às Coordenadorias Regionais de Educação (CREs). O procedimento instituído para o funcionamento, desde o início, se circunscrevia ao Plano de Ação desenvolvido por cada equipe de psicólogos/ assistentes sociais por CRE, além de encaminhamentos de alunos em situações de diversas ordens: indisciplina, dificuldade de aprendizagem, violência nas mais adversas expressões, uso abusivo de drogas, gravidez na adolescência e situações de risco e vulnerabilidade social. Para cada equipe de profissionais da RPE, é estabelecido um grupo de escolas, no formato de territórios, de maneira que todas as escolas da rede possam estar referidas a uma equipe de profissionais. $O$ acompanhamento dessas escolas se dá pela elaboração de um plano de trabalho a partir do foco estabelecido pela CRE, destacando um grupo de escolas prioritárias de acordo com as demandas, objetivos e estratégias do trabalho a ser realizado. Frente a essa organização, nossas propostas com os psicólogos vêm se constituindo através de textos enviados previamente para serem lidos e debatidos entre eles, levando em consideração o trabalho que realizavam e, nos nossos encontros, a proposta é a de discussão coletiva e problematização das práticas, a partir de cenas do cotidiano. Com as coordenadoras realizamos reuniões com a perspectiva de contribuir para a escrita de um outro plano de ação com passagem na Secretaria Municipal de Educação (SME), tornando oficial um deslocamento dos lugares estabelecidos pelas demandas tradicionais de assistência, quem sabe em uma perspectiva transdisciplinar. Elas, por sua vez, também realizam reuniões com os psicólogos a fim de construir os planos de trabalhos locais e a negociação com as coordenadorias das CREs de um trabalho institucional. Durante 2008, realizamos encontros mensais com os psicólogos e, em alguns deles, contamos também com profissionais da educação lotados nas CREs. Ao final de 2008, mais 56 psicólogos, advindos de outro concurso também da SMS, foram nomeados e lotados na SME, perfazendo um total 112 psicólogos na RPE. Em 2009, esse coletivo agregou em sua composição, mais assistentes sociais e representantes da Gerência de Serviço Social na Educação. 